\title{
GREEN JOBS IN THE SERVICE ECONOMY \\ - EMPIRICAL ANALYSIS FOR SELECTED \\ EUROPEAN UNION COUNTRIES
}

\author{
JAN FAZLAGIĆ, ${ }^{1}$ ROBERT SKIKIEWICZ ${ }^{2}$
}

RECEIVED

ACCEPTED

JEL

CLASSIFICATION

KEYWORDS

ABSTRACT

\author{
${ }^{1}$ Poznań University of Economics and Business, POLAND \\ e-mail: jan.fazlagic@ue.poznan.pl \\ ${ }^{2}$ Poznań University of Economics and Business, POLAND \\ e-mail: r.skikiewicz@ue.poznan.pl
}

6 November 2015

1 April 2016

A29, J44, P46

green economy, green jobs, educational market, labour market, demand for training offers, supply of training offers

This article's main goal is to investigate the current trends in the EU labour market regarding the green economy which is dominated by the service sector. These occupations are called "green jobs". Empirical analyses were conducted based on the results of survey carried out among experts in three countries: Poland, Italy and Portugal. The situation of each country was briefly described, and then, the differences between these countries were verified by means of statistical tests. The subject of investigation in the article is to evaluate the education system and the labour market in the context of green jobs in selected countries. The issues related to the training needs in the green economy, are omitted in training programmes offered and available in selected countries. Such observation allows for further assessment of the supply side of the educational market. Furthermore, the demand side of the educational market for each country facilitated the identification of the topics for training courses, which should be included in training programs. In the final part of the article the demand and supply sides of the training offers for each country were compared.

\section{Introduction}

Over the last years a number of publications investigating the issues related to the green jobs market have appeared (e.g. Pawłowski, 2009; Ciżewska, 2012; European Commission 2012a, 2012b, 2012, 2013b). A large number of studies have investigated the relationship between the development of the green economy and the needs of the labour market. We seek to contribute to the field's understanding of green jobs by providing an 
empirical analysis of the training needs for green jobs in selected EU countries. Plainly, the growing green economy needs more skilled professionals. But it is not certain which skills need to be upgraded or developed. The findings contained in this paper are to serve the policy-making purposes. Decision-makers in the European Union need to take knowledge-based decisions in education and labour market policies and this paper may be considered as one of the sources supporting such decisions. The research findings are derived from the research project conducted in the years 2013-2015 by the authors.

The authors of this publication took a hands-on approach and analyzed the actual situation regarding the supply and demand of educational offerings in selected EU countries. The transition to a low-carbon, servicebased, sustainable economy requires a strategic focus on the job market. It also requires more evidence-based decisions on country level beyond traditional sectoral thinking. Green jobs are created in most if not all sectors of economy. The creation of new green jobs depends heavily on the actual skills and competences of workers. Therefore, the educational system in each country should take an active role in aligning the supply and demand for skilled workers.

Currently the share of green jobs in the European Union is relatively small, estimated at only $3.25 \%$ (Colijn, 2014). This share varies depending on the region of the European Union. There are large differences between countries: Denmark, Switzerland and Norway have a fairly large number of jobs with a sustainable component to them, while countries from Central and Eastern Europe are generally lagging behind, with very few green jobs being demanded at all (Colijn, 2014).

Green jobs should not be limited in definition to those jobs which are related to the manufacture of green technologies, e.g. solar panels. There is a number of occupations in the service economy as well. The definition of a green job is therefore very flexible and depends on the consensus among the labour market experts. In a broader, more inclusive understanding of 'green jobs', an advertising agency, which secures a contract to develop a PR campaign promoting the use of public transportation, is supporting the growth of a green economy. Some green jobs are considered 'green' because of the functioning of establishments (e.g., energy efficiency, recycling) when the type of green job being analysed is related to the outputs of establishments (e.g., production of organic food) (Stoevska, Hunter, 2012).

This research paper investigates selected aspects of demand for labour and specific training needs. It is based on an empirical study conducted on a sample of 122 experts in the fields of the green economy and/or the labour market who were recruited from Poland, Italy and Portugal. The questionnaire was distributed and collected in the second quarter of 2014. The purposive sample method was used for the selection of experts, who answered the questions in the survey. The main reason to choose this sampling method was the lack of complete sampling frame, covering all the people who can be considered experts in the field of training courses and green economy. The experts who participated in the survey were employers, employees and the persons who conduct training courses. The empirical data was collected through the participating partners of the e-Green Jobs project. The questionnaire consisted of 18 questions. A Likert scale was used to get opinions about the current state of the education system and the labour market in analysed countries. The questions concerning thematic areas included in the training programmes in each country and the topics that should be included in the training programmes were constructed with the use of alternative nominal scales. 
The following research questions were postulated in the study:

a) What is the current state of the education system and the labour markets?

b) What are the general views on the training needs in the field of green economy among the experts?

\section{The current state of the education system and the labour market in participating countries}

The current state of the education system and the labour market in participating countries varies to some extent. Respondents in all countries strongly agree with the opinion that it is the state that should be responsible for the education for the green economy (3.70) (Figure 1). All respondents agree that the state should do more to promote training programmes in the field of green economy (3.68). In their opinion, the vocational training system of education needs to be improved in order to meet the requirements of the labour market for green jobs (3.63). The differences between countries are relatively small in the case of the abovementioned aspects of the education system and the labour market.

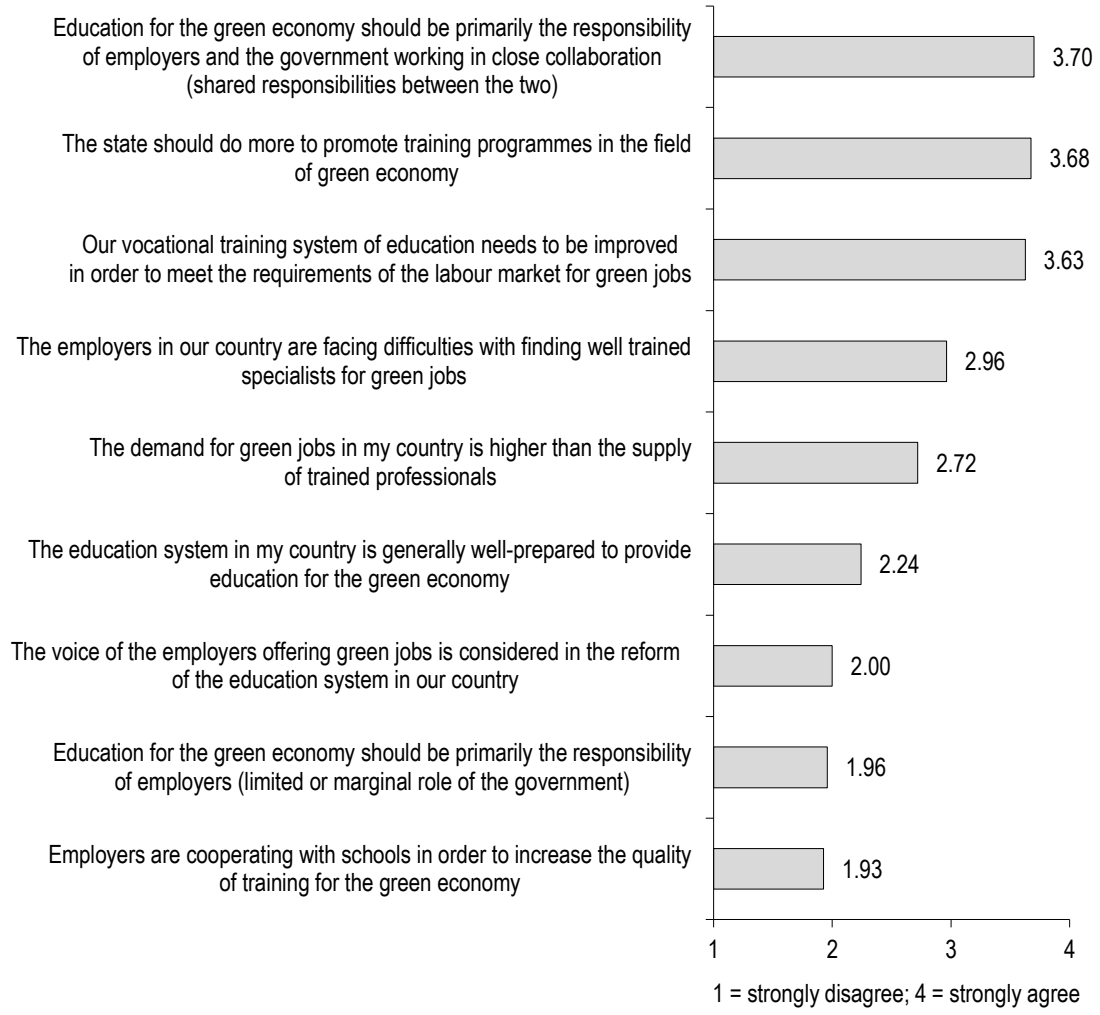

Figure 1. Education system and the labour market for the green jobs

Source: own elaboration. 
Respondents are generally of the opinion that employers are not cooperating with schools in order to increase the quality of training for the green economy (1.93). The most convinced by this statement are the experts from Italy (1.59), while the lowest level of conviction is among respondents from Portugal (2.25) All the experts rather disagree with the statement that education for the green economy should be primarily the responsibility of employers (limited or marginal role of the government) (1.96). The level of approval for the reassignment of this responsibility to employers is lowest in Portugal (1.52). The results of the surveys conducted among experts indicate that there is a problem with taking into account the voice of the employers offering green jobs in the reform of the education system in analyzed countries (2.00). The country where the voice of employers is most valued is Poland (2.12).

\section{Which training programmes are most and least popular?}

The respondents were asked to provide their opinions on the deficiencies in training programmes offered in their countries. They indicated five areas that, according to them, are least frequently offered in the form of training courses.

The analysis of opinions expressed by experts from Poland, Italy and Portugal confirmed that there are differences with regard to particular thematic areas in current training programmes in each country. As a result, the thematic areas that were most often indicated by experts as not included in current training programmes are not the same in the countries compared. On average as much as 12.83 thematic areas were indicated not to be included in training programmes by experts from Poland. Somewhat smaller was the average number of thematic areas that were omitted in Italy (9.79) and Portugal (9.45). The above results indicate that the situation of Poland is in general worse than in other countries.

All the experts from Poland confirmed that in current training programmes, envelope building is not included in sufficient way. Moreover, a relatively high percentage of respondents indicated that the following thematic areas are not included: green policies and business practices (84.1\%), the environmental footprint of global-industrial agriculture (83.3\%), aviation (79.4\%), the "new agriculture" and other agriculture-related areas (79.1\%).

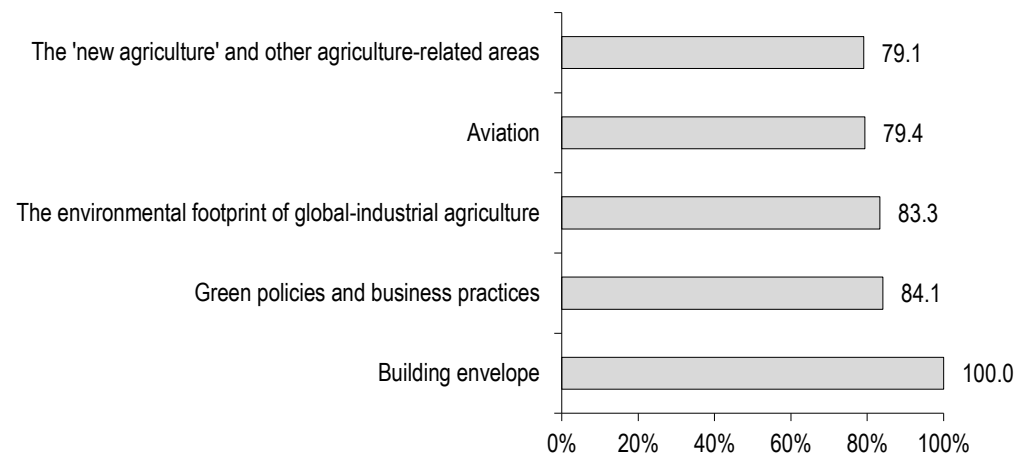

Figure 2. Thematic areas which are most frequently indicated as absent in training programmes in Poland Source: own elaboration. 


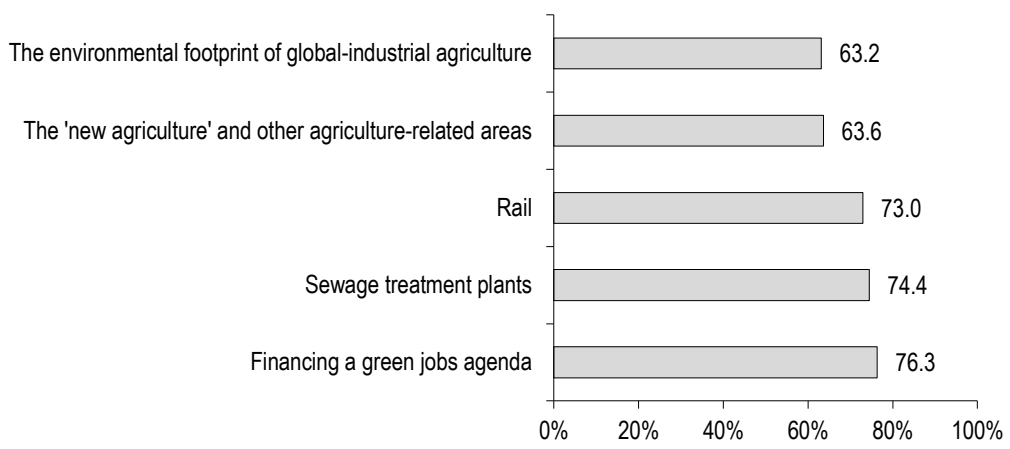

Figure 3. Thematic areas which are most frequently indicated as absent in training programmes in Italy Source: own elaboration.

The level of consensus among the experts was slightly lower in the case of Italy, than in that of Poland and Portugal. As a result, the percentage of indications for the five most commonly recognized as insufficiently covered in training programmes ranged from $63.2 \%$ to $76.3 \%$. The following thematic areas were found in this group: financing a green jobs agenda (76.3\%), sewage treatment plants (74.4\%), rail (73.0\%), the "new agriculture" and other agriculture-related areas (63.6\%), the environmental footprint of global-industrial agriculture (63.2\%).

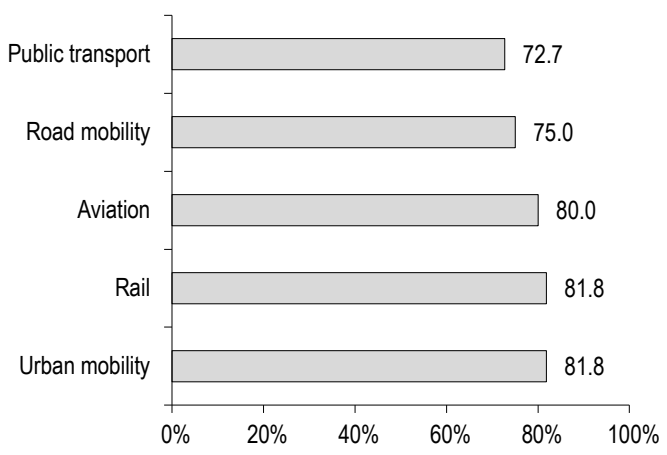

Figure 4. Thematic areas which are most frequently indicated as absent in training programmes in Portugal Source: own elaboration.

In the next step chi-square test for independence was conducted to check if there is a relationship between the country and the range of including thematic areas in training programmes. In the case of almost all thematic areas the chi-square test confirmed that that there is a statistically significant relation between the variable „country” and the topic of training indicated by experts in a specific country. Only in the case of two areas (the environmental footprint of global-industrial and agriculture financing and the green jobs agenda) there was no statistically significant relationship with the country. 
The respondents were asked to provide their opinions on the demand for specific training programmes. Their opinions reflected the possible improvements in the educational systems of their countries regarding the introduction of new topics and subjects for training. Figures 5-7 present the results for Poland, Italy and Portugal.

Almost all the experts from Poland indicated the following thematic areas as being very important: building envelope, public transport, the "new agriculture" and other agriculture-related areas, green policies and business practices, financing a green jobs agenda.

Comparing the thematic areas indicated as the most important for inclusion in training programmes in Poland and Italy, one can find that three of them are the same. Experts from both countries agreed that among the most important are building envelope, the "new agriculture" and other agriculture-related areas, and financing a green jobs agenda, although the higher percentage of indications was in Poland.

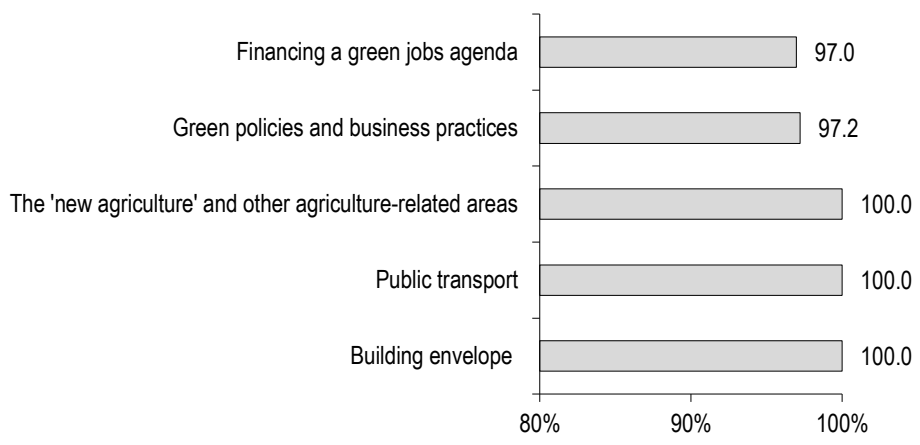

Figure 5. Thematic areas which should be included in the training programmes in Poland Source: own elaboration.

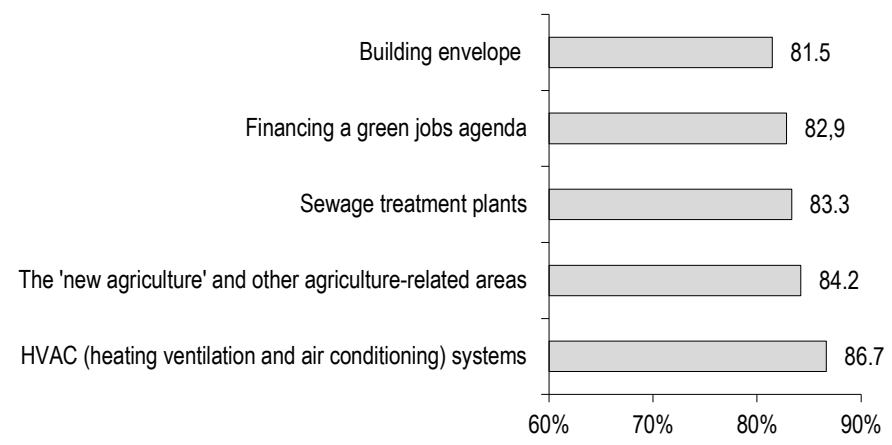

Figure 6. Thematic areas which should be included in the training programmes in Italy

Source: own elaboration. 


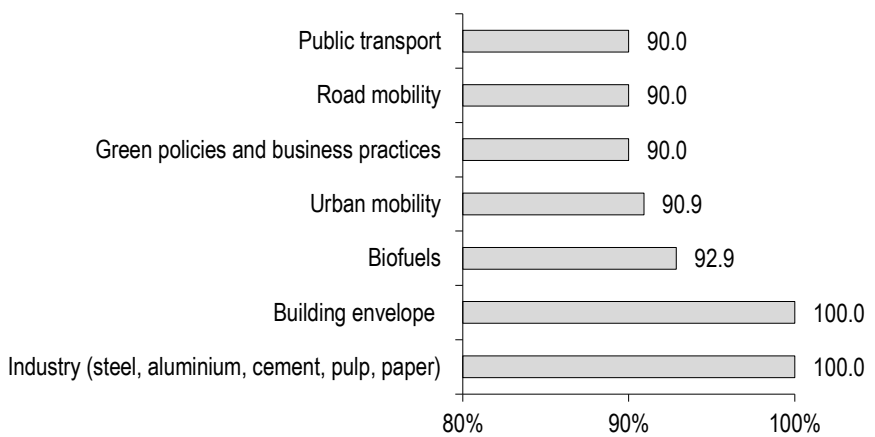

Figure 7. Thematic areas which should be included in the training programmes in Portugal

Source: own elaboration.

The only one thematic area that appeared among the most important for inclusion in training programmes in Poland, Italy and Portugal was building envelope. There are no other ones common to Italy and Portugal. Comparing Portugal and Poland we can find another two areas that are considered the most important: public transport and green policies and business practices.

The relationship between the country and the range of including thematic areas in training programmes were verified with the use of chi-square test for independence. In the case of almost all thematic areas, of which the necessity of inclusion in training programmes was evaluated by experts, the chi-square test confirmed that there is no statistically significant relationship with the country. Only in the case of three thematic areas (green policies and business practices, public transport and the "new agriculture" and other agriculture-related areas) statistically significant relationship was confirmed.

\section{Postulated changes in the education system in relation to a green economy}

The empirical data collected in the survey allows for a comparison of the supply and demand sides of the educational market for skills and competences. The analysis presented in figures postulates changes in the supply of training with the analysis of black holes ( $\mathrm{Y}$ axis in figures below) with the thematic areas where the experts report no training offerings ( $X$ axis in figures below). The point of intersection of the axis was set at the average value obtained for all scores for topics of training which are not currently offered ( $X$ axis) and the average value for all scores for topics of training which should be included in educational offers ( $Y$ axis).

The right upper side of matrix for Poland (Figure 8) shows that the most urgent thematic areas which were indicated relatively often as not included in training programmes, and in the opinion of experts belong to the group of high importance, are the following: building envelope, the "new agriculture" and other agriculture-related areas, green policies and business practices, financing a green jobs agenda, the environmental footprint of globalindustrial agriculture. 


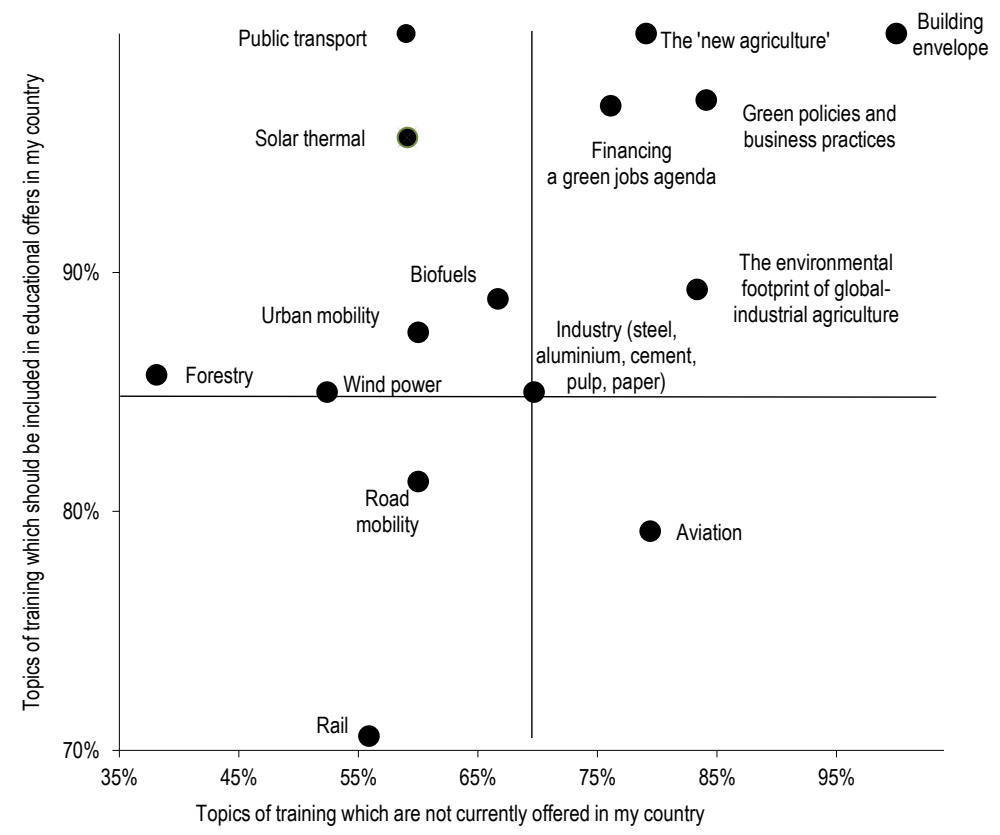

Figure 8. Supply and demand sides of the educational market for training offers in Poland Source: own elaboration.

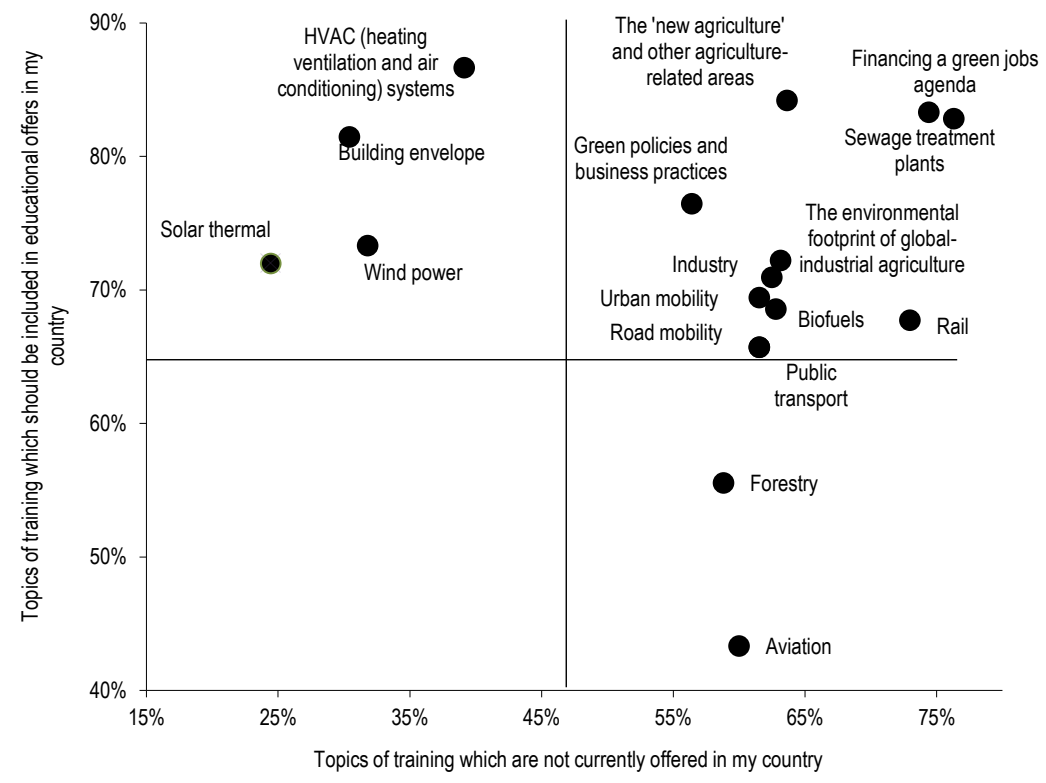

Figure 9. Supply and demand sides of the educational market for training offers in Italy

Source: own elaboration. 
In the case of Italy we can conclude, based on the matrix in Figure 9, that among the thematic those areas which were indicated relatively often as absent in training programmes, and the same time very important, there are the following: financing a green jobs agenda, the "new agriculture" and other agriculture-related areas, sewage treatment plants. High priority should also be given to such areas as green policies and business practices, the environmental footprint of global-industrial agriculture, industry (steel, aluminium, cement, pulp, paper), urban mobility, biofuels and rail.

According to opinions expressed by experts from Portugal, the matrix comparing the supply and demand sides of the educational market (Figure 10) shows that the highest priority should be given to the introduction of training programmes in thematic areas such as road mobility, urban mobility, public transport and rail. Among the very important thematic areas are: biofuels, green policies and business practices, sewage treatment plants, financing a green jobs agenda and forestry.

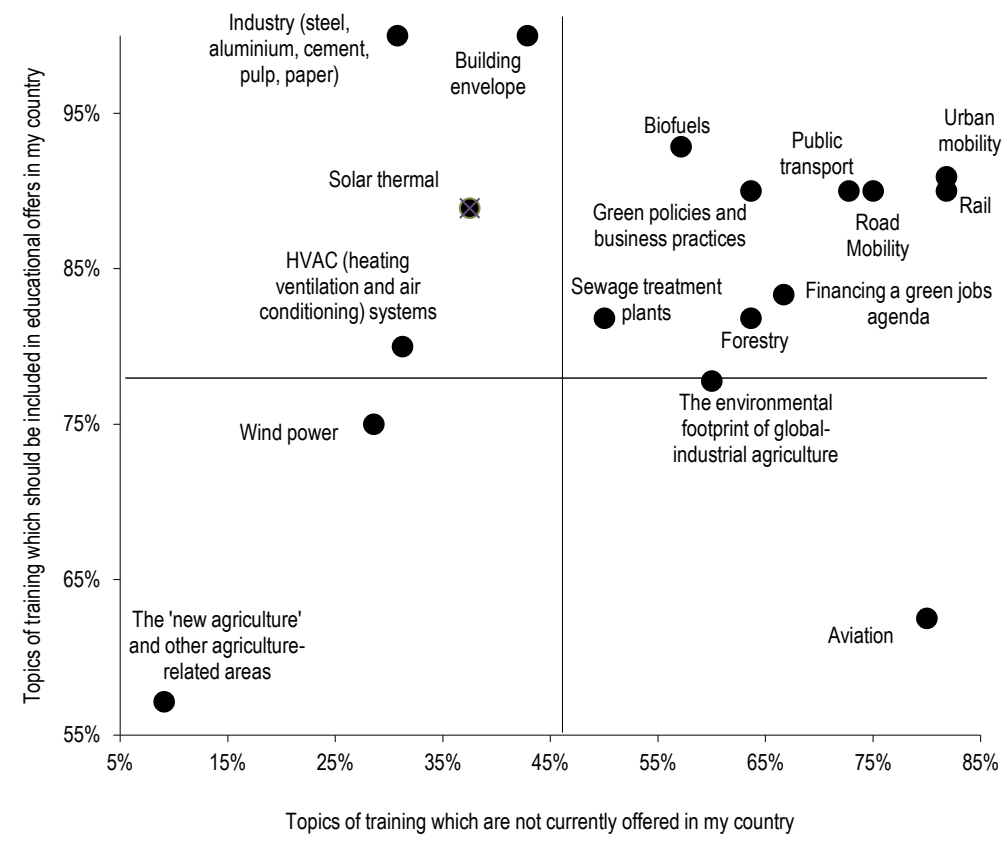

Figure 10. Supply and demand sides of the educational market for training offers in Portugal

Source: own elaboration.

Rarely in training programmes in Portugal do the "new agriculture" and other agriculture-related areas appear as a thematic area. The importance of this area was also rated the lowest. It is worth noticing that "new agriculture" and other agriculture-related areas appeared among the most important to be included in Poland and Italy. 


\section{Conclusions}

The research findings presented in the paper may be useful for policy-making in the field of education systems and labour market development. It is worth to emphasize that in all these countries the state is considered the one who should be responsible for the education for the green economy. The most important in these countries seems to be more cooperation with employers in order to increase the quality of training for the green economy. The voice of the employers offering green jobs should be taken into account in the reform process of the education system in analyzed countries.

The above presented results show that the supply and demand sides of the educational market in Poland, Italy and Portugal are not the same. Between these three countries we can find similarities and differences. The matrix used in empirical analysis of this paper can be very helpful while trying to identify the most important areas to include into training programmes.

\section{References}

Babiker, M., \& Eckaus, R.S. (2006). Unemployment Effects of Climate Policy. MIT Joint Program on the Sciences and Policy of Global Change, Report No. 137, MIT, Cambridge.

California Workforce Education \& Training Needs Assessment For Energy Efficiency, Distributed Generation, and Demand Response (2011). Donald Vial Center on Employment in the Green Economy, Institute for Research on Labor and Employment. Berkeley: University of California.

CEDEFOP (2012). Green skills and environmental awareness in vocational education and training. Research Paper No. 24.

Ciżmowska, A. (2012). Social Policy in the European Sustainable Development Strategy. Problems of Sustainable Development, 7 (2), $51-59$.

Colijn, B. (2014). Green Jobs In Europe And The Increasing Demand For Technical Skills. Neujobs Working Paper. No. 4.2, January.

EEO Review (2010). The Employment Dimension of Economy Greening. European Commission. DG Employment, Social Affairs and Equal Opportunities.

EEO Review (2013). Promoting green jobs throughout the crisis: a handbook of best practices in Europe. European Commission, DG Employment, Social Affairs and Equal Opportunities.

European Commission (2012a). Towards a Job-Rich Recovery, COM (2012) 173.

European Commission (2012b). Exploiting the employment potential of green growth. Staff Working Document (2012) 92.

European Commission (2013b). Thematic Event on "Pathways to green jobs: strategies and policy options for a sustainable job-rich recovery".

European Commission, DG Employment, Social Affairs and Inclusion (2013a). Public Employment Services and Green Jobs. Analytical paper, August.

Greening (2013). Rapporto Greenitaly 2013. Nutrire il futuro. Available: http://www.symbola.net/assets/files/GREENITALY-2013_ 1383234863.pdf (12.11.2015).

ILO (2011). Skills for Green Jobs: A Global View.

ILO/UNEP (2008). Green Jobs: Towards Decent Work in a Sustainable Low Carbon World.

OECD (2012). OECD Employment Outlook, What Green Growth Means For Workers And Labour Markets: An Initial Assessment.

Pawłowski, A. (2009). Rewolucja Rozwoju Zrównoważonego. Problems of Sustainable Development, 4 (1), 65-76.

Stoevska, V., \& Hunter, D. (2012). Proposals for the statistical definition and measurement of green jobs. International Labour Office Geneva.

Cite this article aS: Fazlagić, J., Skikiewicz, R. (2016). eGreen Jobs in the service economy - empirical analysis for selected European Union countries. European Journal of Service Management, 18 (2), 13-22. DOI: 10.18276/ejsm.2016.18-02. 